\title{
Docking Studies on Cyclooxygenases-2 Inhibitors based on Potential Ligand Binding Sites
}

\author{
Karima Nekkaz \\ Laboratory of Naturals \\ Products and Bio actives- \\ LASNABIO. Faculty of \\ Sciences -Department of \\ Chemistry.University of \\ Tlemcen- BP 119, 13000. \\ ALGERIA, \\ Salima Merghache \\ Laboratory of Naturals \\ Products and Bio actives- \\ LASNABIO.Faculty of \\ Sciences -Department of \\ Chemistry.University of \\ Tlemcen- BP 119, 13000. \\ ALGERIA,
}

\author{
Ismail Daoud \\ Laboratory of Naturals \\ Products and Bio actives- \\ LASNABIO.Faculty of \\ Sciences -Department of \\ Chemistry.University of \\ Tlemcen- BP 119, 13000. \\ ALGERIA
}

Naouel Khebichat

Laboratory of Naturals

Products and Bio actives-

LASNABIO.Faculty of

Sciences -Department of

Chemistry.University of

Tlemcen- BP 119, 13000.

ALGERIA

\author{
Kawther Younes \\ Laboratory of Naturals \\ Products and Bio actives- \\ LASNABIO.Faculty of \\ Sciences -Department of \\ Chemistry.University of \\ Tlemcen- BP 119, \\ 13000.ALGERIA \\ Said Ghalem \\ Laboratory of Naturals \\ Products and Bio actives- \\ LASNABIO.Faculty of \\ Sciences -Department of \\ Chemistry.University of \\ Tlemcen- BP 119, \\ 13000.ALGERIA
}

\begin{abstract}
In the last years, the development of the drug for the treatment of inflammation is very fast. The inflammation is a first-rate example of a disease that symbolizes turmoil in normal host defense systems. COX-2 is an oxido-reductase having a role in prostaglandin biosynthesis, inflammatory responses and in cardiovascular events. COX-2 has gained special focus on research since past few decades. The compounds isolated from plants have good inhibitory effects against cyclooxygenase.

In this study, Molecular modeling and docking analysis were used to predict and understand interactions between COX-2 and some compounds isolated from Artemisia arborescensL. The approach is applicable in engineering 3D structures of enzymatic models, and studying interactions of active site residues with ligands show that the three compounds: $\mathbf{L}_{\mathbf{9}}, \mathbf{L}_{\mathbf{8}}$ and $\mathbf{L}_{\mathbf{4}}$ give the best results, so they may be effective as the potential inhibitor compound against COX-2 protein and can be evaluated as anti-inflammatory drug molecule using clinical trials.
\end{abstract}

\section{Keywords}

Anti-inflammation, COX-2, Cycloprodigiosin, Molecular docking, Artemisia arborescensL, Interactions

\section{INTRODUCTION}

Inflammation is a protective measure taken by the organism to eliminate the injurious stimuli; however the use of antiinflammatory substances can be an effective tool in the therapeutic treatment of the diseases. In this context, medicinal plants and their isolated compounds are employed worldwide in folk medicine to treat different inflammatory conditions, such as lung and skin inflammations. In the continuous search for new bioactive natural products against inflammation, essential oils are increasingly being referred to as a rich source of such products; therefore the antiinflammatory activity of some essential oils and their isolated components, i.e., the monoterpenes. Most investigations concerning the anti-inflammatory potential of agents are undertaken in rodents with the use of different test models such as the carrageenan, formalin and arachidonic acid induced paw edema, among others, and in vitro and ex vivo protocols, which may employ essential oils or monoterpenes [1].

Essential oils are a mixture of volatile and natural substances, characterized by a strong odor and produced by aromatic plants as secondary metabolites. They have a wide range of applications and have been commercially important for the pharmaceutical, food, cosmetic and perfume industries. The variety of pharmacological activities found in essential oils is remarkable. This class of natural products is attracting the interest of many researchers to investigate its potential as drugs for the treatment of various diseases. The number of clinical and pre-clinical studies about essential oils and their chemical constituents is increasing every year. Furthermore, there are many bioactive substances that are synthesized from constituents of essential oils. Some pharmacological activities of these oils, such as anti-tumoral and anti-nociceptive actions are related to their anti-inflammatory effects [2-6].

Artemisia is one of the genera of Asteraceae family with many important medicinally valuable essential oils that have been widely used for a variety of medicinal purposes for many years [7].

Artemisia species are frequently utilized for treatment of diseases such as hepatitis, cancer, infections by malaria, fungi, bacteria, viruses and inflammation $[8,9]$.

In the other hand the anti-inflammatory drugs are the most important class of widely used therapeutics for the treatment of inflammation and pain. Cyclooxygenases control the complex conversion of arachidonic acid to prostaglandins and thromboxanes, which trigger as autocrine and paracrine chemical messengers many physiological and pathophysiological responses [10, 11-13]. 
COX-2, an isoform of COX family, is highly inducible in response to proinflammatory stimuli, cytokines and consequential in exaggerated prostaglandin release [14].

Previous studies demonstrated that COX-1 and COX-2 are inhibited by the NSAIDs randomly and this leads to the ulceration in the gastric parts and additionally affects renal functions [15-17].

In this study, computations on the interactions at the active site of COX-2 were carried out for nine ligands. All these ligands have shown to be competitive inhibitors for the COX2 activity. We applied a molecular docking protocol to explore the protein-ligand interactions. The study also focuses on the comparison between the inhibitory potentials of the novel compounds on the COX-2. In future, it may be necessary to explore the development of potential new antiCOX-2 drugs for treating cancer and inflammation.

\section{MATERIALS AND METHODS \\ 2.1 Experimental study}

These results taken from experimental paper which published in"African Journal of Pharmacy and Pharmacology Vol. 6(42), pp. 2912-2921, 15 November, 2012" by our laboratory

\section{Plant material}

The aerial part of A. arborescensL. was collected from the region near Tlemcen in the West Northern of Algeria: Bidar (131 m, 35 $\left.4^{\circ} 0^{\prime \prime} \mathrm{N}, 2^{\circ} 6^{\prime} 0^{\prime \prime} \mathrm{W}\right)$, during the flowering period (May, 2010). Botanical identification of plant was conducted by Prof. Noury BENABADJI - Laboratory of Botany, Department of Biology, University of AboubekrBelkaïd, Tlemcen, Algeria. Before extraction, plant was extended by ground, in one layer, in an open room protected from the sun. During drying time, plant was turned over to allow homogeneous drying.

\section{Essential oil analysis}

You found the Gas chromatography (GC) and Gas chromatography-mass spectrometry (GC/MS) analysis in [18].

\section{Component identification}

Identification of the components was based:

1) On comparison of their GC retention indices (RI) on nonpolar and polar columns with those of authentic compounds or literature data [19-27].

2) On comparison of their recorded mass spectra with those of a computer library provided by instrument software and MS literature data [19-21, 28-31]. RI was determined with C7 to C25 alkane standards as reference.

\section{Chemical composition}

The essential oil was obtained by hydrodistillation using a Clevenger apparatus, from the aerial part of $A$. arborescens. The blue essential oil obtained was analyzed by GC and GC/MS techniques. The relative percentages and the RI of the major detected components were shown in Table 1.
Table 1. Major Compounds of the A. arborescens $L$. Essential oil from the West Northern of Algeria [1]

\begin{tabular}{|c|c|c|c|c|c|}
\hline $\begin{array}{l}\mathbf{N} \\
\mathbf{0}\end{array}$ & $\begin{array}{c}\text { Compoun } \\
\text { ds }\end{array}$ & $\mathbf{I R}_{\text {Lit }}^{\mathrm{a}}$ & $\mathbf{I R}^{\mathbf{b}}$ & $\mathbf{I R}^{\mathbf{c}}$ & $\begin{array}{c}\text { Essential } \\
\text { oil }^{\mathrm{d}}\end{array}$ \\
\hline \multicolumn{5}{|c|}{ Monoterpenehydrocarbon } & EOCT \\
\hline L & Myrcene & 979 & 980 & 1154 & 2.7 \\
\hline $\begin{array}{l}\mathrm{L} \\
2\end{array}$ & $\begin{array}{l}\gamma- \\
\text { Terpinene }\end{array}$ & 1047 & 1048 & 1238 & 3.1 \\
\hline $\mathbf{L}$ & p-Cymene & 1011 & 1012 & 1261 & 1.3 \\
\hline \multicolumn{6}{|c|}{ Oxygenatedmonoterpene } \\
\hline $\begin{array}{l}\mathrm{L} \\
4\end{array}$ & $\begin{array}{l}\text { Cis- } \\
\text { sabinene- } \\
\text { hydrate }\end{array}$ & 1083 & 1085 & 1509 & 3.4 \\
\hline $\begin{array}{l}\mathbf{L} \\
5\end{array}$ & Camphor & 1123 & 1124 & 1505 & 32.8 \\
\hline $\begin{array}{l}\text { L } \\
6\end{array}$ & $\begin{array}{l}\text { Terpinen- } \\
\text { 4-ol }\end{array}$ & 1161 & 1163 & 1590 & 8.9 \\
\hline L & $\beta$-Thujone & 1103 & 1097 & 1411 & 1.0 \\
\hline \multicolumn{6}{|c|}{ Sesquiterpenehydrocarbon } \\
\hline $\begin{array}{r}\text { L } \\
8 \\
\end{array}$ & $\begin{array}{l}\text { Chamazul } \\
\text { ene }\end{array}$ & 1713 & 1707 & 2360 & 8.7 \\
\hline \multicolumn{6}{|c|}{ Oxygenatedsesquiterpene } \\
\hline $\mathbf{L}$ & Elemol & 1535 & 1532 & 2061 & 1.6 \\
\hline
\end{tabular}

${ }^{a}$ Retention indices of literature on the apolar column reported from Arômes Library (1987-2011), König (2001), Adams (2001), Velasco-Negueruela et al. (2002), Dabiri and Sefidkon (2003), Bendimerad et al. (2005), Cha (2007), Dib et al. (2010) and Khamsan et al. (2011). ${ }^{\mathbf{b}}$ Retention indices on the apolar Rtx-1 column. ${ }^{\mathrm{C}}$ Retention indices on the polar Rtx-Wax column. ${ }^{\mathbf{d}}$ Percentages are given on the apolar column except for components with identical RI (percentages are given on the polar column), tr, trace $(<0.05 \%)$; EO, essential oil of aerial part of $A$. arborescens,; CT, Chetouane.

\subsection{Molecular Docking study}

$\mathrm{X}$-ray crystallographic 3-dimensional structure of mouse Cyclooxygenase, 1CX2 atomic coordinates was taken from protein data bank (PDB) [32] to study protein-ligand interactions. $1 \mathrm{CX} 2$ is a Cyclooxygenase-2 (prostaglandin synthase-2 or COX-2) enzyme with EC Number: 1.14.99.1 classified under Oxido-reductase class of enzymes, complexed with a selective inhibitor S58 with 4 chains, with $3.0 \mathrm{~A}^{\circ}$ resolution and $0.216 \mathrm{R}$-value respectively. Computational analysis was carried out on chain A of 1CX2. The nine COX-2 inhibitor molecules $\mathbf{L}_{1}$ : Myrcene, $\mathbf{L}_{2}: \gamma$ Terpinene, $\mathbf{L}_{\mathbf{3}}$ : p-cymene, $\mathbf{L}_{\mathbf{4}}$ : cis-Sabinene-Hydrate, $\mathbf{L}_{\mathbf{5}}$ : Camphor, $\mathbf{L}_{\mathbf{6}}$ : Terpinen-4-ol, $\mathbf{L}_{\mathbf{7}}$ : $\beta$-Thujone, $\mathbf{L}_{\mathbf{8}}$ :Chamazulene, $\mathbf{L}_{\mathbf{g}}$ :Elemol were selected to study the associated physicochemical parameters and protein-ligands interactions. All ligands (Figure 1) were drawing by software ISIS Draw [33].

Mol Dock Scorescoring function was employed to predict the binding energy for active site residue-ligand interactions and docking studies computed for all ligands using MVD program that predicted interactions in terms of Dock score. 
<smiles>C=CC(=C)CCC=C(C)C</smiles>

Myrcene<smiles>CC(C)[C@]12CC[C@@](C)(O)C1C2</smiles>

\section{Cis-Sabinene hydrate}<smiles>CC(C)[C@]12CC[C@@H](C)[C@H](C1)C2=O</smiles>

$\beta$-Thujone<smiles>CC1=CCC(C(C)C)=CC1</smiles><smiles>Cc1ccc(C(C)C)cc1</smiles>

Y-Terpinene<smiles>CC12CCC(CC1=O)C2(C)C</smiles>

Camphor
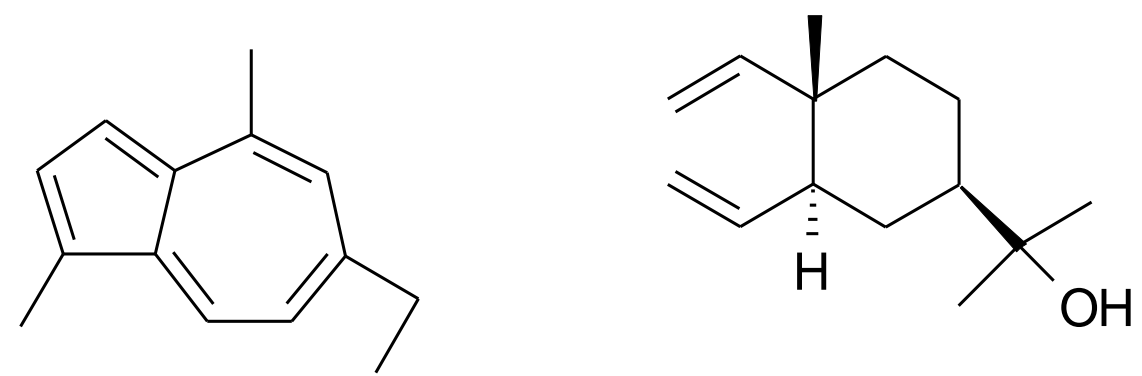

Elemol

Fig.1: Chemical structure ofthe ligands. $L_{1}$ : Myrcene, $L_{2}: \gamma$-Terpinene, $L_{3}$ :p-cymene, $L_{4}$ :cis-Sabinene-Hydrate, $L_{5}$ : Camphor, $L_{6}:$ Terpinen-4-ol, $L_{7}: \beta$-Thujone, $L_{8}:$ Chamazulene, $L_{9}$ :Elemol.

The full geometrical optimization of the food dyes $\mathbf{L}_{\mathbf{1 - 9}}$ (Figure 1) in the gas phase were carried out at the level of semi-empirical AM1 method [34], as well as density functional theory (DFT) [35] using a gradient technique [36,37] and 6-31G* $[38,39]$ basis set. The DFT calculations were carried out with the B3LYP functional, in which Becke's nonlocal exchange $[40,41]$ and the Lee-Yang-Parr correlation functional [42]. Semi-empirical and DFT calculations were performed using GAUSSIAN 03 for Windows programpackage [43]. All calculations were done on a Pentium IV PC computer [44].
Table 2: Energies, volume and surface of each ligands.

\begin{tabular}{cccc}
\hline Compound & $\begin{array}{c}\text { Conformer } \\
\text { energy (u.a) }\end{array}$ & $\begin{array}{c}\text { Volume } \\
\AA^{3}\end{array}$ & $\begin{array}{c}\text { Surface } \\
\AA^{2}\end{array}$ \\
\hline $\mathbf{L}_{\mathbf{1}}$ & -390.63606 & 583.82 & 379.87 \\
$\mathbf{L}_{\mathbf{2}}$ & -390.68333 & 547.31 & 356.63 \\
$\mathbf{L}_{\mathbf{3}}$ & -389.51115 & 533.81 & 348.88
\end{tabular}




\begin{tabular}{llll}
$\mathbf{L}_{\mathbf{4}}$ & $\mathbf{- 4 6 7 . 1 0 0 5 8}$ & $\mathbf{5 6 3 . 6 0}$ & 350.12 \\
$\mathbf{L}_{\mathbf{5}}$ & -465.92356 & 523.82 & 327.24 \\
$\mathbf{L}_{\mathbf{6}}$ & -467.11326 & 560.17 & 350.52 \\
$\mathbf{L}_{\mathbf{7}}$ & -465.90166 & 550.17 & 349.03 \\
$\mathbf{L}_{\mathbf{8}}$ & $\mathbf{- 5 4 3 . 1 0 1 9 7}$ & $\mathbf{6 5 7 . 4 3}$ & 404.88 \\
$\mathbf{L}_{\mathbf{9}}$ & $\mathbf{- 6 6 2 . 4 2 6 0 9}$ & $\mathbf{7 6 3 . 0 4}$ & 441.80 \\
\hline
\end{tabular}

Table 3: Chemical properties of our cavities

\begin{tabular}{cc}
\hline Cavities & $\begin{array}{c}\text { Volume } \\
\AA^{3}\end{array}$ \\
\hline Cavity1 & 139.776 \\
Cavity2 & 417.792 \\
Cavity3 & 894.976 \\
Cavity4 & 95.232 \\
Cavity5 & 59.392 \\
\hline
\end{tabular}

\subsubsection{The Simulation Details}

The structure of the protein was corrected for missing atoms or unknown units using Molegro Virtual Docker (MVD2011) [45-47] program, graphical-automatic software (http://molegro.com/mvd-product.php).
Docking was performed by using Molegro Virtual Docker (MVD) software package. The identification of ligand binding modes is done by iteratively evaluating a number of candidate solutions (ligand conformations) and estimating the energy of their interactions with the macromolecule. MVD performs flexible ligand docking, so the optimal geometry of the ligand will be determined during the docking. The MolDock [48] scoring function (MolDock Score) used by MVD is derived from the PLP scoring functions originally proposed by Gehlhaar et al. and later extended by Yang et al [49]. The MolDock scoring function further improves these scoring functions with a new hydrogen bonding term and new charge schemes.

\subsubsection{The Docking}

To obtain better potential binding sites in the cyclooxygenase2 (PDB ID: 1CX2), a maximum of five cavities was detected using default parameters. The volume and surface area details were given as (Table 3$)$. The volume of cavity $2\left(417,792 \mathrm{~A}^{3}\right)$ was found to be highest and in center of enzyme than the other cavities, also we found that the reference ligand of $1 \mathrm{CX} 2$ is fixed in cavity $1\left(139,776 \mathrm{~A}^{3}\right)$. Out of the detected cavities, cavity 1 and 2 was selected for further studies (figure 2 ). The chosen cavity was further refined using side chain minimization by selection of an add-visible option set at a maximum of 10,000 steps per residue and at a maximum of 10,000 global steps. The grid resolution was $0.30 \AA$; the max iterations were 1,500 ; the max population size was 50 and the energy threshold was 100 .was $0.30 \AA$; the max iterations were 1,500; the max population size was 50 and the energy threshold was 100 .

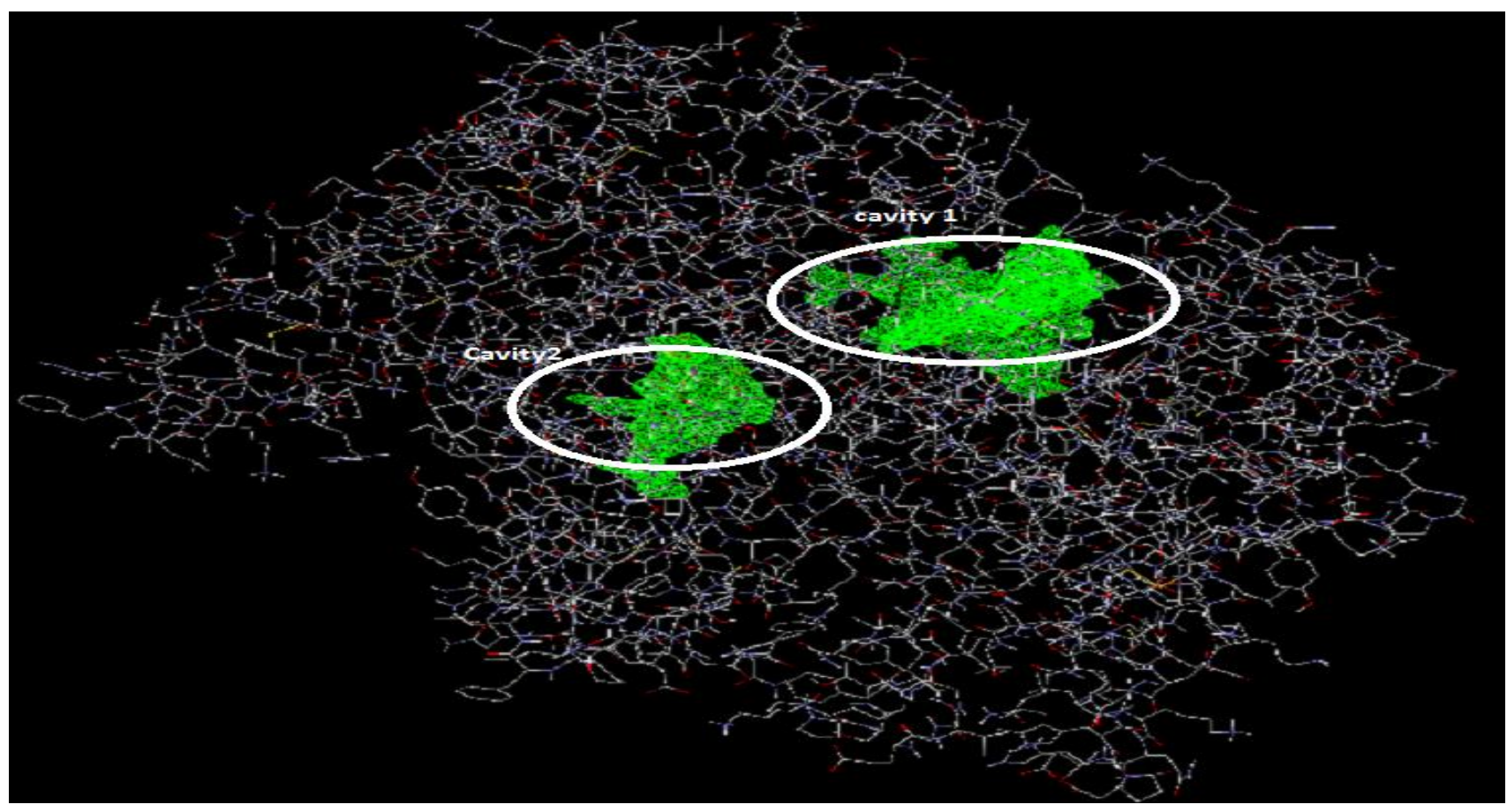

Fig.2: Graphical interface with the cavities (cavity 1 and cavity 2 indicated by ellipses) identified by MolDock 


\section{RESULTS AND DISCUSSION}

\subsection{Study of Ligand-Substrate Interaction}

We evaluate the designed compounds through docking techniques using MVD program. We docked the designed compounds on one of the crystal structures of cyclooxygenase II available through the RCSB Protein Data Bank (PDB entry 1CX2). The scoring functions of the compounds were calculated from minimized ligand protein complexes. In order to compare the binding affinity of the newly our ligands, we docked compounds $\mathbf{L}_{\mathbf{1 - 9}}$ into the empty binding site of cyclooxygenase II with its bound inhibitors (1CX2).

S58 ligand with surrounding active site residues within 3.5 $\mathrm{A}^{\circ}$, hydrogen bonding interactions and the spatial orientation in binding pocket is given in Figure 3. The interacting residues surrounding the ligand within $3.5 \mathrm{~A}^{\circ}$ distance are His90, Arg120, Gln192, Val349, Leu352, Ser353, Tyr355, Leu359, Tyr385, Arg513, Ala516, Phe518, Val523 and Ala527 respectively [17]

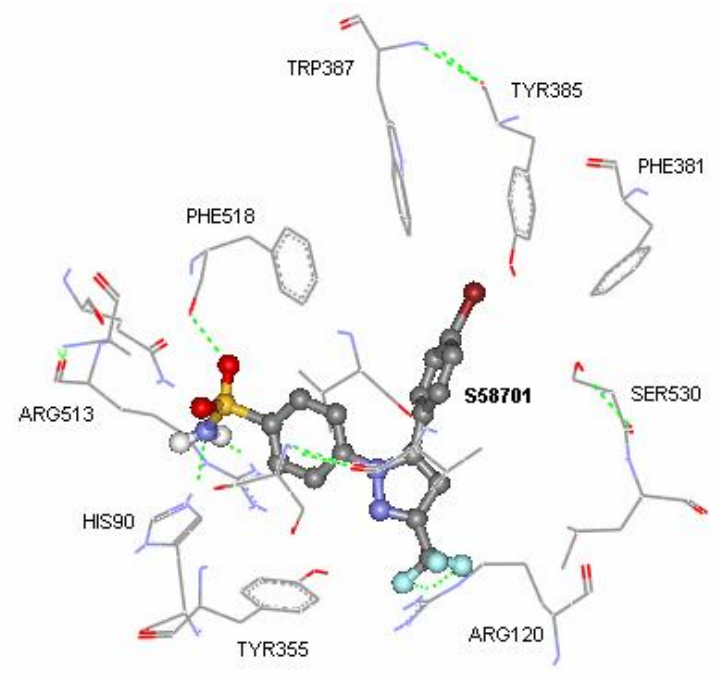

Fig.3: Spatial orientation of S58 crystal ligand within 3.5 $\mathrm{A}^{\circ}$ active site residues. Hydrogens are removed for clarity and hydrogen bonds are shown in green dotted lines

\subsection{Virtual screening}

The nine ligands molecules having minimum energy were screened out as the possible inhibitors for COX-2(Table 4).

In cavity1: All selected molecules were having energy MolDock score as follows: Ligand $\mathbf{L}_{\mathbf{1}}$ is having minimum energy MolDock score $-75.4128 \mathrm{Kcal} / \mathrm{Mol}$. Ligand $\mathbf{L}_{\mathbf{2}}$ is having -67.0613 Kcal/Mol. Ligand $\mathbf{L}_{\mathbf{3}}$ is having -69.2694 and Ligand $\mathbf{L}_{\mathbf{4}}$ is having energy MolDock score -77.2643 $\mathrm{Kcal} / \mathrm{Mol}$. Ligand $\mathbf{L}_{\mathbf{5}}$ is having energy MolDock score-54.23. Ligand $\mathbf{L}_{\mathbf{6}}$ is having energy MolDock score -66.9286. Ligand $\mathbf{L}_{7}$ is having energy MolDock score -75.5506 , Ligand $\mathbf{L}_{8}$ is having energy MolDock score -94.1948 , Ligand $\mathbf{L}_{\mathbf{9}}$ is having energy MolDock score -99.933. Also in cavity 2: All selected molecules were having energy MolDock score as follows: Ligand $\mathbf{L}_{\mathbf{1}}$ is having minimum energy MolDock score 89.3531Kcal/Mol. Ligand $\mathbf{L}_{2}$ is having $-81.2475 \mathrm{Kcal} / \mathrm{Mol}$. Ligand $\mathbf{L}_{\mathbf{3}}$ is having -79.5281 and Ligand $\mathbf{L}_{\mathbf{4}}$ is having energy MolDock score $-84.3366 \mathrm{Kcal} / \mathrm{Mol}$. Ligand $\mathbf{L}_{\mathbf{5}}$ is having energy MolDock score -58.4656. Ligand $\mathbf{L}_{\mathbf{6}}$ is having energy MolDock score -83.1421. Ligand $\mathbf{L}_{7}$ is having energy MolDock score -90.67, Ligand $\mathbf{L}_{\mathbf{8}}$ is having energy MolDock score -116.244, Ligand $\mathbf{L}_{\mathbf{9}}$ is having energy MolDock score 105.498 . 
Table 4. Docking results of nine ligands with $1 \mathrm{CX} 2$ in the both cavities

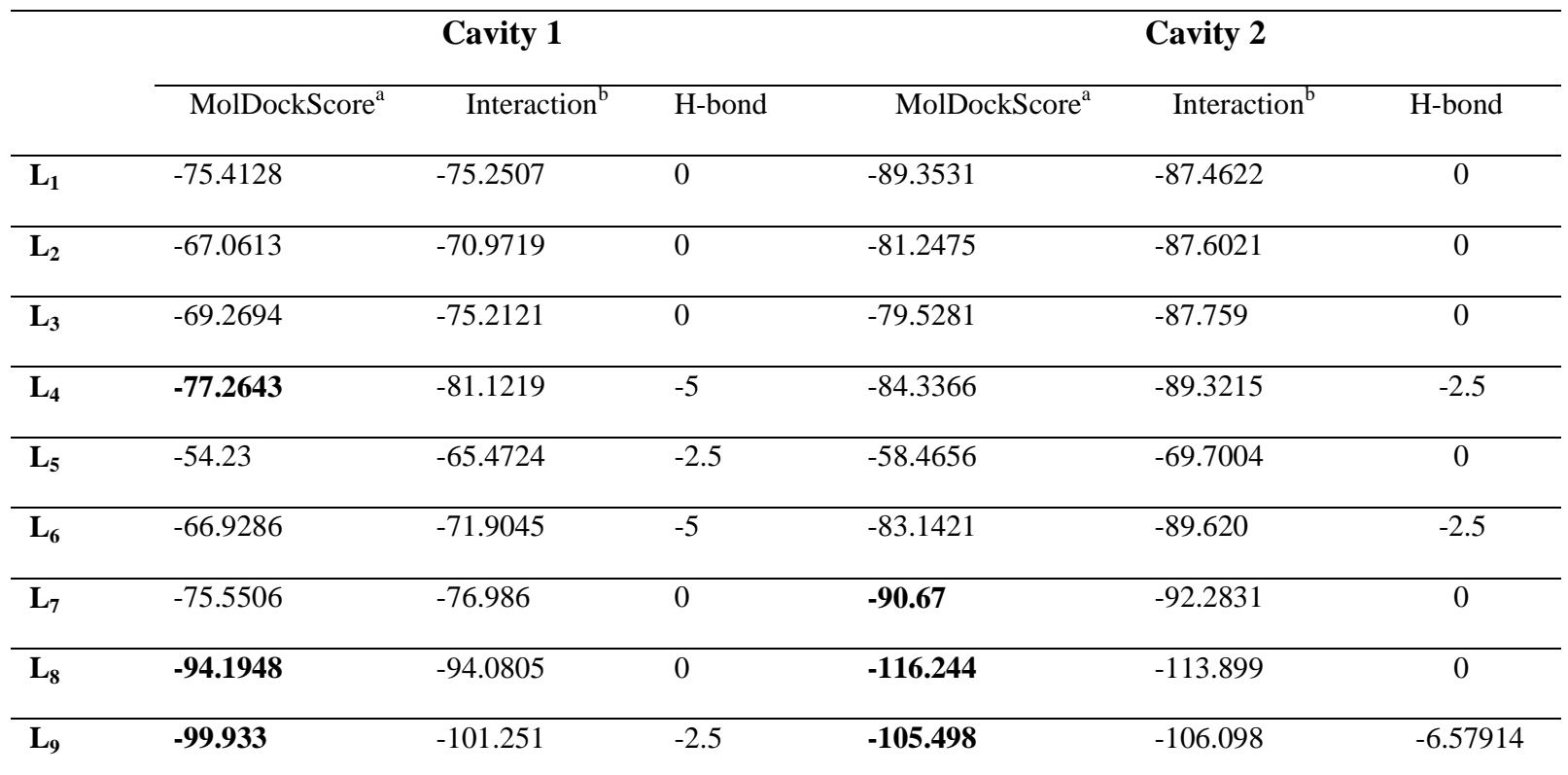

${ }^{\mathrm{a}}$ MolDock score calculated by summing the external ligand interaction (protein-ligand interaction) and internal ligand interaction score using Virtual Molecular Viewer 1.2.0.

${ }^{\mathbf{b}}$ The total interaction energy between the pose and the target molecules(s). 


\section{CONCLUSION}

Docking studies confirm that the main interaction of COX-2 inhibitors with enzyme is Hydrogen bond and Hydrophobic interactions with the binding pockets made by hydroxyl groups. The fifty compounds were identified by GC/MS analysis of $A$. arborescens. Nine of them were docked using Molegro Virtual Docker (MVD) software package. Among the nine compounds $\mathbf{L}_{\mathbf{9}}, \mathbf{L}_{\mathbf{8}}$ and $\mathbf{L}_{\mathbf{4}}$ have respectively low values of energy MolDock score:-99.93, -94.1948 and 77.2643. These results indicate that the $\mathbf{L}_{\mathbf{9}}$ act as potential binding sites for the design of highly selective and potent COX-2 inhibitors in the both cavities (1 and 2).

This information has potential implications to understand the mechanism of COX-2 related enzymatic inhibition reactions, and also applicable in the prediction of more effective inhibitors and engineering 3D structures of other enzymes as well.

Hence, it is concluded that that $\mathbf{L}_{\mathbf{9}}$ : Elemol could be a potent anti-inflammatory target molecule against COX-2 which may be worth for further clinical trials.

\section{ACKNOWLEDGMENTS}

Our thanks to the experts who have contributed towards development of the template

\section{REFERENCES}

[1] Rita de C. S. Sá, Luciana N. A and Damião P. S. 2013.A Review on Anti-Inflammatory Activity of Monoterpenes. Molecules, 18, 1227-1254.

[2] De Sousa D. P. 2012. Medicinal Essential Oils: Chemical, Pharmacological and Therapeutic Aspects, 1st ed.; Nova Science Publishers: New York, NY, USA; p. 236.

[3] Santos, F. A and Rao, V. S. N. 2000.Anti-inflammatory and antinociceptive effects of 1,8-cineole aterpenoid oxide present in many plant essential oils. Phytother. Res, 14, 240-244.

[4] Valério D. A. R, Cunha T. M, Arakawa N. S, Lemos H. P, da Costa F. B, Parada C. A, Ferreira S. H, Cunha F. $\mathrm{Q}$ and Verri J. W. A. 2007.Anti-inflammatory and analgesic effects of the sesquiterpene lactone budlein A in mice: Inhibition of cytokine production-dependent mechanism. Eur. J. Pharmacol., 562, 155-163.

[5] Juergens U. R and Stober M. V. 1998.The antiinflammatory activity of 1-menthol compared to mint oil in human monocytes in vitro: A novel perspective for its therapeutic use in inflammatory diseases. Eur. J. Med. Res., 3, 539-545.

[6] Wu X, Li X, Xiao F, Zhang Z, Xu Z and Wang H. 2004.Studies on the analgesic and anti-inflammatory effect of bornyl acetate in volatile oil from Amomumvillosum.Zhong Yao Cai, 27, 438-439.

[7] Ahameethunisa A. R and Hopper W. 2010. Antibacteri al activity of Artemisia nilagirica 1 eaf extracts against clinical and phytopathogenic bacteria. BMC $\mathrm{C}$ omplement .Altern. Med. 1 0: 6.

[8]Jeon D. 2007.Chemical composition and anti bacterial activity against oral bacteria by essential oil of Artemisia iwayomogi.J .Bacteriol.Virol. 37 (3): 1 29-1 36.

[9] Nezhadali A, Akbarpour M, Zarrabi S. 2008. Chemical composition of the essential oil from the aerial parts of Artemisia herba. E. J. Chem. 5(3):557-561.
[10] Gehan H. H, Ghaneya S. H, Nahla A. F and Amal Y, 2011., Design, Synthesis, and Docking Studies of Novel Diarylpyrazoline and Diarylisoxazoline Derivatives of Expected Anti inflammatory, and Analgesic Activities., Life Science Journal, Volume 8, Issue 1, 2011.

[11] Kurumbail R. G, Kiefer J. R and Marnett L. J. 2001. Cyclooxygenase enzymes: catalysis and inhibition. Curr.Opin.Struct. Biol., 11: 752-60.

[12] Marnett L. J. 2000. Cyclooxygenase mechanisms.Curr.Opin.Chem. Biol. 4, 545-52.

[13] Fitzpatrick F. A. 2004. Cyclooxygenase enzymes: regulation and function. Curr. Pharm. Des., 10: 577-88.

[14] Saranyah K., Sukesh.K., and Dinesh Kumar K. Lilly M. Saleena. 2011. Structure Based Pharmacophore Modeling and Virtual Screening for Identification of Novel Inhibitor for Cyclooxygenase-2, International Conference on Bioscience, Biochemistry and Bioinformatics. IPCBEE., $5: 373-377$.

[15] Saranyah K, Sukesh K, Dinesh Kumar K and Lilly M.S.2011. Structure Based Pharmacophore Modeling and Virtual Screening for Identification of Novel Inhibitor for Cyclooxygenase-2,International Conference on Bioscience, Biochemistry and Bioinformatics, 5:1-5.

[16] Gehan H. H, Ghaneya S. H, Nahla A. F and Amal Y. 2011. Design, Synthesis, and Docking Studies of Novel Diarylpyrazoline and Diarylisoxazoline Derivatives of Expected Anti-inflammatory, and Analgesic Activities, Life Science Journal, Volume 8, Issue 1.

[17] Adinarayana K. P. S, Ashoka, R. P and Ajay B. P. 2012. Structural Studies on Docking Selective COX-2 Inhibitors, Journal of Bioinformatics \&Research , 1(1): 21-26.

[18] Younes K, Merghache S, Djabou N, Merghache D, Muselli A, Tabti1 B and Costa J. 2012. Chemical composition, antibacterial and antioxidant activities of a new essential oil chemotype of Algerian Artemisia arborescensL. African Journal of Pharmacy and Pharmacology; 6(42), 2912-2921.

[19] Arômes library of Laboratory of Chemistry of Natural Products (1987- 2011). University of Corse, Corte, France.UMR CNRS.p 6134.

[20] König W. A, Hochmuth D. H and Joulain D. 2001.Terpenoids and related constituents of essential oils.Library of Mass Finder 2.1, University of Hamburg, Institute of Organic Chemistry, Hamburg, Germany.

[21] Adams R. P. 2001. Identification of Essential Oil Components by Gas Chromatography / Quadrupole Mass Spectroscopy.Allured Publishing. Carol Stream, IL, USA.

[22] Velasco-Negueruela A, Pérez-Alonso M. J, Palà-Paùl J, Inigo A and Lopez G. 2002. Leaf essential oils of JuniperusnavicularisGandoger. Bot. Complutensis, 26:85-91.

[23] Dabiri M and Sefidkon F. 2003. Chemical composition of the essential oil of Nepetaracemosa L am. From Iran.FlavourFragr. J. 18:157-158

[24] Bendimerad N, Taleb S. A, Benabadji A. B, Fernandez X, Valette L and Lizzani- Cuvelier L. 2005. Composition and antibacterial activity of Pseudocytisusintergrifolius 
(Salisb).essential oil from Algeria. J. Agric. Food Chem. 53:2947-2952.

[25] Cha J. D. 2007. Chemical composition and antibacterial activity against oral bacteria by essential oil of Artemisia iwayomogi. J. Bacteriol. Virol. 37(3):129-136.

[26] Dib M. A, Djabou N, Desjobert J. M, Allali H, Tabti B, Muselli A and Costa J. 2010. Characterization of volatile compounds of DaucuscrinitusDesf.Headspace solid phase microextraction as alternative technique to hydrodistillation. Chem. Cent. J. 4(16):1-15.

[27] Khamsan S, Liawruangrath B, Liawruangrath S, Teerawutkulrag A, Pyne S. G and Garson M. J. 2011. Antimalarial, anticancer, antimicrobial activities and chemical constituents of essential oil from the aerial parts of CyperuskyllingiaEndl. Rec. Nat. Prod. 5(4):324-327.

[28] NIST (National Institute of Standards and Technology) (1999). PC Version 1.7 of the NIST/EPA/NIH Mass Spectral Library Perkin Elmer Corporation, Norwalk, CT.

[29] Mc Lafferty F. W and Stauffer D. B. 1988.The Wiley/NBS Registry of Mass Spectral Data. WileyInterscience, New York. p 4.

[30] Mc Lafferty F. W and Stauffer D. B. 1994.Wiley Registry of Mass Spectral Data. Mass Spectrometry Library Search System, Bench-Top/PBM version 3.10d, Palisade, Newfield. p 6.

[31] Hochmuth D. 2006.Mass Spectral Library "Terpenoids and related constituents of essential oils".Library of Mass Finder 3.0, Hamburg, Germany.

[32] 1CX2: 3-dimensional structure downloaded from http://www.rcsb.org/pdb .

[33] ISIS Draw, a 2-dimensional chemical molecule drawing software: http://www.mdli.com/

[34] Stewart J. J. P. 2007. Optimization of parameters for semi-empirical methods V: modification of NDDO approximations and application to 70 elements. J Mol Model; 13(12): 1173-213.

[35] Labanowski J. K and Andzelm J. W. 1991. editors. Density functional methods in chemistry. New York: Springer Verlag;,p.443.

[36] Baker J. 1986. An algorithm for the location of transition states. J ComputChem; 7(4): 385-95.
[37] Schlegel H. B. 1994. Editor. Modern electronic structure theory: geometry optimization on potential energy surfaces. Singapore: World Scientific.

[38] Hehre W. J, Radom L, Schleyer P. V. R and Pople J.A. 1986. Ab initio molecular orbital theory. New York: Wiley.

[39] Hariharan P. C, Pople J. A. 1973. The influence of polarization functions on molecular orbital hydrogenation energies. TheorChimActa; 28(3): 213-22.

[40] Becke A. D. 1988. Density-functional exchange-energy approximation with correct asymptotic behavior.Phys Rev A; 38(6): 3098-100.

[41] Becke A. D. 1993. A new mixing of HartreeeFock and local density-functional theories. J. Chem. Phys; 98(3): 1372-7.

[42] Lee C, Yang W and Parr R. G. 1988. Development of the Colle-Salvetti correlation-energy formula into a functional of the electron density.Phys Rev B; 37(4):7859.

[43] Frisch M.J, Trucks G.W, Schlegel H.B, Scuseria G.E, Robb M.A and Cheeseman J.R, et al. 2004. Gaussian 03, Revision D.01. Wallingford, CT: Gaussian, Inc.

[44] Ismail Daoud, Mourad Mesmoudi, Said Ghalem, 2013. MM/QM study: Interactions of copper(II) and mercury(II) with food dyes in aqueous solutions., 4) 49 56.

[45]da Cunha E. F. F, Martins R. C.A, Albuquerque M. G. 2004.LIV-3D-QSAR model for estrogen receptor ligands. J Mol Mod; 10(5): 297-304.

[46] Elaine F. F, da Edilaine F .B, Aline A. O and Teodorico C. R. 2010. Molecular modeling of Mycobacterium tuberculosis DNA gyrase and its molecular docking study with gatifloxacin inhibitors. J BiomStructDyn; 27(5): 619-625.

[47] Ramalho T. C, Rocha M. V. J, da Cunha E. F. F and Freitas M. P. 2009. The search for new COX-2 inhibitors. Expert OpinTher Pat; 19(9): 1193-1228.

[48] Thomsen R and Christensen M. H.2006. MolDock: a new technique for highaccuracy molecular docking.J Med Chem; 49(11): 3315-3321.

[49] Schulz H, Dale E, Karimi-Nejad Y and Oefner C. 2009. Structure of human endothe-linonverting enzyme I complexed with phosphoramidon.J MolBiol; 385(1): 178-187. 